\title{
Effect of reflow profile parameters on surface mount chip resistor solder joint shear strength
}

\author{
Peter K. Bernasko ${ }^{1}$, Sabuj Mallik ${ }^{1}$, G. Takyi $^{2}$ \\ ${ }^{1}$ Electronics Manufacturing Engineering Research Group, School of Engineering at Medway, University of Greenwich, Chatham \\ Maritime, Kent, ME4 4TB, UK \\ ${ }^{2}$ Department of Mechanical Engineering, Kwame Nkrumah University of Science and Technology, Kumasi, Ghana
}

Email address:

P.Bernasko@gre.ac.uk (P. K. Bernasko),gtakyi.soe@knust.edu.gh (G. Takyi)

\section{To cite this article:}

Peter K. Bernasko, Sabuj Mallik, G. Takyi. Effect of Reflow Profile Parameters on Surface Mount Chip Resistor Solder Joint Shear Strength. International Journal of Materials Science and Applications. Vol. 3, No. 5, 2014, pp. 254-259.

doi: $10.11648 /$ j.ijmsa.20140305.27

\begin{abstract}
The focus of this study is on the effect of reflow parameters on the joint shear strength. Eight reflow profiles were developed using four factors at two levels of Taguchi design of experiment for 1206, 0805 and 0603 chip resistors. Normal probability and main effect plots were used to provide a complete profile of the effect of reflow parameters on the chip resistor solder joint shear strength. The Normal Probability plots show effect of some reflow parameters on shear strength. Some data points did not fall on the best fit line.These outliers indicate parameter effects. The 1206 chip resistor shear strength value of $74.85 \mathrm{~N}$ lies outside the best fit line indicating that some of the parameters are critical and significantly affect the response value. The results of the Main Effect plots help identify the unknown critical parameters in the probability plots. It indicates that the shear strength of 1206 chip resistor depends on the peak temperature, time above liquidus and preheat slope but not on cooling rate. In the case of the 0805 chip resistor, there were no exceptional departures from the line fitted to the data. It can be assumed that the factors and the levels considered here have no significant effect on the response. The normal probability plot of the 0603 chip resistor shows that the $46.68 \mathrm{~N}$ shear strength lies outside the fitted line. This means that the factors and settings (run 3) can be further modified to improve the response. The factors which affected the 0603 resistor from the main effect plot are preheat slop and cooling rate.The results of the 1206 chip resistor show the highest shear force of $74.8 \mathrm{~N}$ using a peak temperature setting of $230^{\circ} \mathrm{C}$ (low level). The 0805 and 0603 chip resistors recorded the highest shear forces of $68.32 \mathrm{~N}$ and 46.48 respectively using a temperature of $245^{\circ} \mathrm{C}$ (high level). The higher temperature may have contributed to the lower shear force due to the growth of brittle intermetallic compound in the case of the 0805 and 0603 chip resistors.
\end{abstract}

Keywords: Reflow Parameters, Shear Strength, Normal Probability Plot, Solder Joint, Chip Resistors

\section{Introduction}

In the Electronics industry, reflow soldering is considered as an important process in the formation of solder joints. The reflow profile has become a major concern due to its effect on the solder joint reliability and quality [1]. One of the most important factors in electronics manufacturing process for determining soldering defect rate is the reflow profile. Defects such as tombstoming, cracking, cold joints, excessive intermetallics formation, bridging, poor wetting and solder balling in electronics assembly and packaging are attributed to improper reflow profile setting parameters[2]. These parameters are very critical because they determine the shape, microstructure and strength of the solder joints [3].

Beddingfield and Higgins [4] in their work revealed that the popcorn defect in the solder joints is due to different reflow methods and process parameter performance. It was also pointed out that vapour phase reflow with preheat gave better results as compared with vapour phase reflow without preheat condition. In a study conducted by Munamarty and McCluskey [5] on single parameter comparison or broad comparison stated that the infra-red reflow preheat rate affect the package delamination. Ranjit et al [6] reported that if reflow profile is poorly designed such that temperature is not high enough to melt the solder 
bumps and exhaust the flux before reaching the melting point, defects will be produced in the solder joints.

The peak temperature of lead-free reflow profile for solder bumps on FR4 substrate was found to be a significant parameter that determines the thickness of intermetallic compound layer and microstructure quality [7]. However, the microstructure of the solder joint depends on interfacial reaction between the substrate and solder. The effect of substrate and solder interfacial reaction also determines the reliability of the solder joint[8-10]. In a research work [11], it was concluded that both reflow peak temperature and time above liquidus of the lead-free reflow profile are critical factors that determine the shear strength of the $\mathrm{SnAgCu}$ solder joints. Arra [12] stated that the peak temperature and the time above liquidus during reflow process are the most critical parameters affecting solder joint reliability. Accordingly, in the case of $\mathrm{SnAgCu}$ reflow soldering, a peak temperature of $230^{\circ} \mathrm{C}$ is recommended for achieving quality solder joints. Moreover, a peak reflow temperature of $241{ }^{\circ} \mathrm{C}$ led to more robust solder joints than profiles with peak temperatures of 220 and $228{ }^{\circ} \mathrm{C}$. However, the use of high peak temperature reflow profile to ensure good wettability and performance of $\mathrm{SnAgCu}$ solder joints is complicated [13].

The shear force of solder joint is mainly attributed to the intermetallic compound layer thickness and the microstructure of bulk solder joint. The difference in solder joint shear force depends on the type of solder alloy and microstructure during reflow soldering. Moreover, a factor preferentially considered for strong solder joint is faster cooling rate. This results in finer grain size and eventually produces quality and strong solder joint [14]. Pan et al [15] reported that the effect of reflow profile on solder joint shear strength is critical because the shear force of the solder joint depends on the initial reflow profile settings. Additionally, Webster et al [16] in their work stated that the effect of thermal shock on the solder joint shear strength should be considered in electronics manufacturing assembly. Furthermore, failure of these joints does not disrupt the functionality of the electronic package or assembly but have great impact on safety critical application [17]. Many researchers have reported on the effect of reflow profile on lead-free solder joints shear force, however there is no established parameters for reflow profile and shear force on solder joint reliability. Therefore, it is extremely important to have the reflow profile engineered properly in order to achieve high shear strength, high yield and high reliability of solder joints.

\section{Experimental Procedure}

The importance of evaluating the shear force of different surface mount chip resistors after reflow soldering was considered paramount in this work. The main features of the test vehicle design are shown in figure 1 . It consists of copper board of size $(100 \times 160 \times 1.6) \mathrm{mm}$ thickness. The chip resistors 1206, 0805 and 0603 were used to form the solder joints. A total of sixty copper boards were used in this study. Each board contains sixty three chip resistors made up of twenty one each of 1206, 0806 and 0603 resistors as shown in figure 1 . The solder paste used for printing on a DEK 260 stencil printer was Sn-3.8Ag-0.7Cu, with type 3 particle size distributions and 89 wt per cent metal content. The printing process parameters used include a pressure of $8 \mathrm{~kg}$, separation speed of $100 \%$, speed of $50 \mathrm{~mm} / \mathrm{s}$ and snap off of $0 \mathrm{~mm}$.

It is, however, necessary to thoroughly understand the effect of reflow soldering profile parameters such as peak temperature, cooling rate, time above liquidus and preheat slope on chip resistor solder joint reliability. Therefore, Taguchi design technique was employed for the experimental test runs. The two levels and four factors were used to design the experimental test runs. The experimental parameters used for the study are shown in table 1 . The experimental test runs were performed by employing the combinations of the reflow profile parameters shown in table 2. A typical sample of the reflow profile is shown in figure 2. The test vehicles were subjected to the same environmental condition of 24 hours isothermal ageing at a temperature of $150^{\circ} \mathrm{C}$ and at a constant humidity of $35 \%$ $\mathrm{RH}$. After the isothermal ageing, the chip resistor solder joints were sheared with Dage-4000PXY Bond tester as shown in figure 3.Test speed (i.e. displacement rates) of $700 \mu \mathrm{m} / \mathrm{s}$ was used throughout the tests. The maximum shear distance employed was $3000 \mu \mathrm{m}$ and a test load of $196 \mathrm{~N}$. The shear height and the land speed of the shear test in this work were $100 \mu \mathrm{m}$ and $500 \mu \mathrm{m} / \mathrm{s}$, respectively.

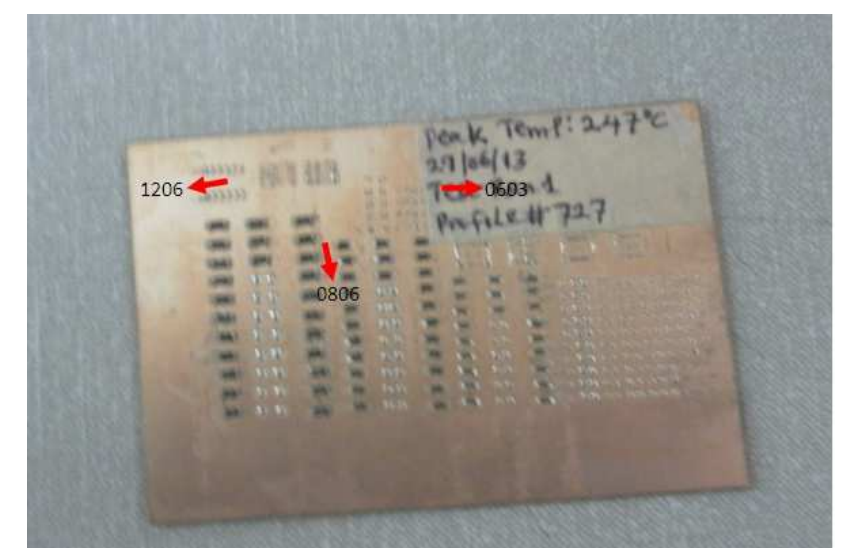

Figure 1. Copper board with an array of 1206, 0806 and 0603 chip resistors

Table 1. Experimental parameters used for the study

\begin{tabular}{lll}
\hline \multirow{2}{*}{ Factors } & Levels & \\
\cline { 2 - 3 } & High (2) & Low (1) \\
\hline $\mathrm{A}=$ Preheat Slope & $1.2^{\circ} \mathrm{C} / \mathrm{sec}$ & $1.0^{\circ} \mathrm{C} / \mathrm{sec}$ \\
$\mathrm{B}=$ Time above Liquidus & $60 \mathrm{secs}$ & $45 \mathrm{secs}$ \\
$\mathrm{C}=$ Peak Temperature & $245^{\circ} \mathrm{C}$ & $230^{\circ} \mathrm{C}$ \\
$\mathrm{D}=$ Cooling Rate & $100 \%$ & $60 \%$ \\
\hline
\end{tabular}

Let; High level $(\mathrm{H})=2$, Low level $(\mathrm{L})=1, \mathrm{~A}=$ Preheat slope, $\mathrm{B}=$ Time above, $\mathrm{C}=$ Peak temperature, $\mathrm{D}=$ Cooling rate 
Table 2. Combinations of reflow profile parameters used

\begin{tabular}{|c|c|c|c|c|c|c|c|c|}
\hline \multirow{2}{*}{ Experiment No. } & \multicolumn{4}{|c|}{ Factors } & \multirow{2}{*}{ Preheat Slope $\left({ }^{\circ} \mathrm{C} / \mathrm{sec}\right)$} & \multirow{2}{*}{$\begin{array}{l}\text { Time Above Liquidus } \\
\text { (sec) }\end{array}$} & \multirow{2}{*}{$\begin{array}{l}\text { Peak } \\
\text { Temperature }\left({ }^{\circ} \mathrm{C}\right)\end{array}$} & \multirow{2}{*}{$\begin{array}{l}\text { Cooling Rate } \\
\text { (\%) }\end{array}$} \\
\hline & $\mathbf{A}$ & B & $\mathbf{C}$ & D & & & & \\
\hline 1 & 2 & 2 & 2 & 2 & 1.2 & 60 & 245 & 100 \\
\hline 2 & 2 & 2 & 1 & 1 & 1.2 & 60 & 230 & 60 \\
\hline 3 & 2 & 1 & 2 & 1 & 1.2 & 45 & 245 & 60 \\
\hline 4 & 2 & 1 & 1 & 2 & 1.2 & 45 & 230 & 100 \\
\hline 5 & 1 & 2 & 2 & 1 & 1.0 & 60 & 245 & 60 \\
\hline 6 & 1 & 2 & 1 & 2 & 1.0 & 60 & 230 & 100 \\
\hline 7 & 1 & 1 & 2 & 2 & 1.0 & 45 & 245 & 100 \\
\hline 8 & 1 & 1 & 1 & 1 & 1.0 & 45 & 230 & 60 \\
\hline
\end{tabular}

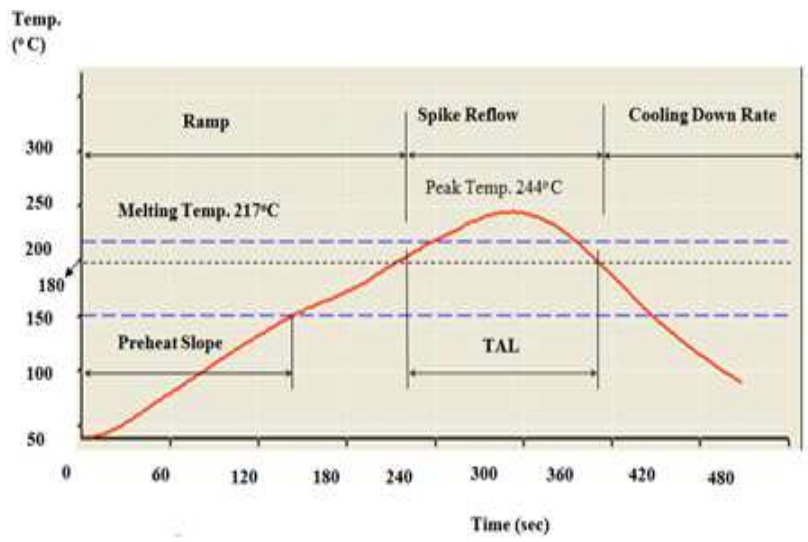

Figure 2. Ramp-to-Spike reflow profile

\section{Results and Discussions}

Table 3a shows the reflow profile parameters for the 1206 chip resistor which resulted in the highest average shear force. An average shear force of $74.85 \mathrm{~N}$ was observed. The parameters and their settings are: preheat slope of 1.2, time above liquidus of 60 seconds, peak temperature of $230^{\circ} \mathrm{C}$ and cooling rate of $60 \%$. This indicates that solder joint shear strength is maximised by setting preheat slope at a high level (2), time above liquidus at a low level (1), peak temperature at a low level (1) and cooling rate at a high level (2). However, a low shear force of $61.68 \mathrm{~N}$ was observed with a reflow profile parameters of preheat slope of 1.0 , time above liquidus of 60 seconds, peak temperature of $245^{\circ} \mathrm{C}$ and cooling rate of $60 \%$. It can be deduced that the higher the peak temperature, the lower the shear forcer. This might be due to the growth of brittle intermetallic compound layer thickness. The results however, is different in the case of the 0805 chip resistor. The highest shear force of $68.32 \mathrm{~N}$ for 0805 chip resistor was obtained by setting a preheat slope of $1.0^{\circ} \mathrm{C} / \mathrm{s}$ (low level or 1), time above liquidus of 45 seconds (low level), peak temperature of $245^{\circ} \mathrm{C}$ (high level) and a cooling rate of $100 \%$ (high level) as shown in table $3 \mathrm{~b}$. The highest shear force of $46.48 \mathrm{~N}$ was obtained for 0603 chip resistor using preheat slope of $1.2^{\circ} \mathrm{C} / \mathrm{s}$, time above liquidus of 45 sec, cooling rate of $60 \%$ and a peak temperature of $245^{\circ} \mathrm{C}$ as shown in table $3 \mathrm{c}$.
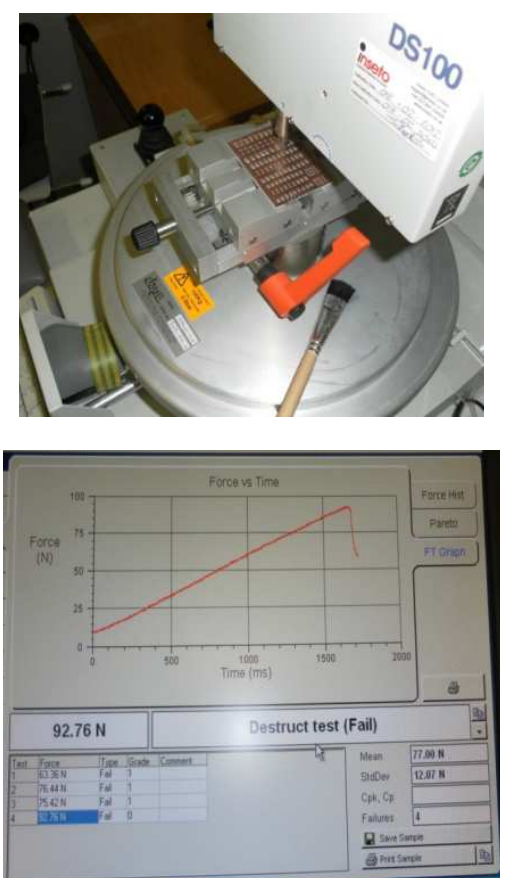

Figure 3. Shear test and force against time plot

Table 3a. Test run combination and shear force of 1206 chip resistor

\begin{tabular}{llllll}
\hline & Preheat Slope & Time above Liquidus & Peak Temperature & Cooling Rate & Shear Force (N) \\
\hline $\mathbf{1}$ & 1.2 & 60 & 245 & 100 & 65.54 \\
$\mathbf{2}$ & 1.2 & 60 & 230 & 60 & 74.85 \\
$\mathbf{3}$ & 1.2 & 45 & 245 & 60 & 67.60 \\
$\mathbf{4}$ & 1.2 & 45 & 230 & 100 & 72.94 \\
$\mathbf{5}$ & 1.0 & 60 & 245 & 60 & 61.78 \\
$\mathbf{6}$ & 1.0 & 60 & 230 & 100 & 64.33 \\
$\mathbf{7}$ & 1.0 & 45 & 245 & 100 & 68.63 \\
$\mathbf{8}$ & 1.0 & 45 & 230 & 60 & 67.94 \\
\hline
\end{tabular}


Table 3b. Test run combination and shear force of 0805 chip resistor (edited)

\begin{tabular}{|c|c|c|c|c|c|}
\hline & Preheat Slope & Time above Liquidus & Peak Temperature & Cooling Rate & Shear Force $(\mathbf{N})$ \\
\hline 1 & 1.2 & 60 & 245 & 100 & 62.17 \\
\hline 2 & 1.2 & 60 & 230 & 60 & 55.19 \\
\hline 3 & 1.2 & 45 & 245 & 60 & 62.72 \\
\hline 4 & 1.2 & 45 & 230 & 100 & 58.05 \\
\hline 5 & 1.0 & 60 & 245 & 60 & 51.45 \\
\hline 6 & 1.0 & 60 & 230 & 100 & 66.00 \\
\hline 7 & 1.0 & 45 & 245 & 100 & 68.32 \\
\hline 8 & 1.0 & 45 & 230 & 60 & 58.41 \\
\hline
\end{tabular}

Table 3c. Test run combination and shear force of 0603 chip resistor (edited)

\begin{tabular}{|c|c|c|c|c|c|}
\hline & Preheat Slope & Time above Liquidus & Peak Temperature & Cooling Rate & Shear Force (N) \\
\hline 1 & 1.2 & 60 & 245 & 100 & 42.23 \\
\hline 2 & 1.2 & 60 & 230 & 60 & 42.35 \\
\hline 3 & 1.2 & 45 & 245 & 60 & 46.48 \\
\hline 4 & 1.2 & 45 & 230 & 100 & 40.21 \\
\hline 5 & 1.0 & 60 & 245 & 60 & 40.78 \\
\hline 6 & 1.0 & 60 & 230 & 100 & 42.12 \\
\hline 7 & 1.0 & 45 & 245 & 100 & 39.21 \\
\hline 8 & 1.0 & 45 & 230 & 60 & 43.13 \\
\hline
\end{tabular}

\subsection{Normal Probability Plot of Reflow Parameters}

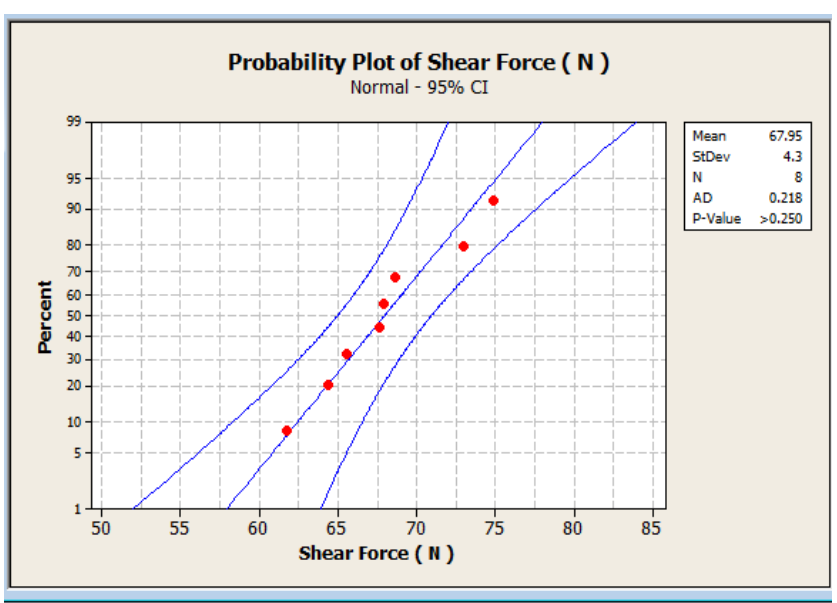

Figure 4a. Normal probability plot of 1206 chip resistor

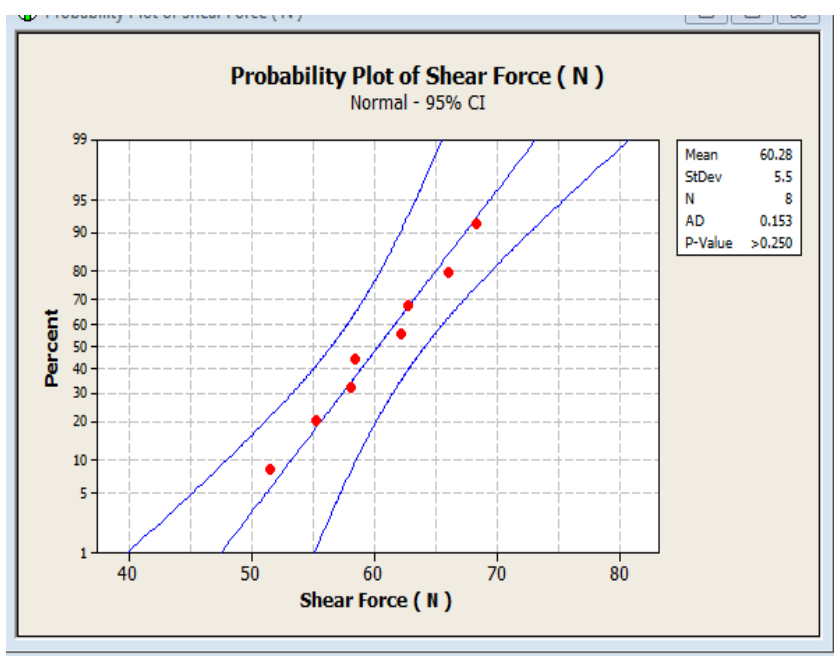

Figure 4b. Normal probability plot of 0805 chip resistor

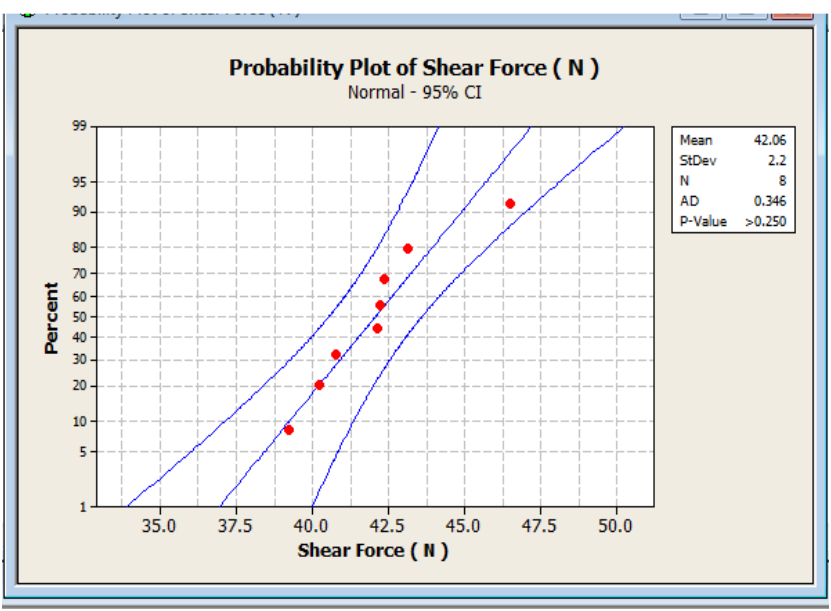

Figure 4c. Normal probability plot of 0603 chip resistor

The normal probability plot of the chip resistor was used to evaluate the effect of process parameters on the strength of the solder joint. Figure $4 \mathrm{a}$ is a normal probability plot of reflow parameter effects on 1206 shear strength solder joints. The results indicate that some factors have significant effect on the reflow soldering process. This is due to the fact that not all data points fall on the best fit line. The outliers $[74.85 \mathrm{~N}, 72.94 \mathrm{~N}$ and $68.63 \mathrm{~N}$ ] indicate that some parameters have significant effect on the integrity of the 1206 solder joint [18]. In the case of the 0805 chip resistor, there were no exceptional departures from the line fitted to the data. It can be assumed that the factors and the levels considered here have no significant effect on the response. In the case of the normal plot for the 0603 chip resistor, three points $(46.48 \mathrm{~N}, 43.23 \mathrm{~N}$ and $42.35 \mathrm{~N})$ lie outside the fitted line as shown in figure 4c. These outliers also indicate factor effect on shear strength. The main effect plots discussed in section 3.2 can be used to determine the parameters that have significant effect on the response variables. 


\subsection{Main Effect of Reflow Parameters}

The main effect plots of the reflow soldering parameters on 1205, 0805 and 0603 chip resistor solder joints are shown in figures $5 \mathrm{a}, 5 \mathrm{~b}$ and $5 \mathrm{c}$ respectively. The main effect plots help us identify the critical factors that are unknown in the normal probability plots. During the reflow soldering of 1206 chip resistor, the cooling rate shows no effect on the reflow process while the peak temperature, time above liquidus and preheat slope affected the reflow process as shown in figure $5 \mathrm{a}$. Figure $5 \mathrm{~b}$ shows a different behaviour of reflow parameter effect on 0805 chip resistor. The preheat slope and peak temperature did not affect the reflow process but the time above liquidus and cooling rate slightly affected the process. Figure 5c shows the effect of reflow soldering process parameters on 0603 chip resistor. The parameters which slightly affected the process include preheat slope and cooling rate.

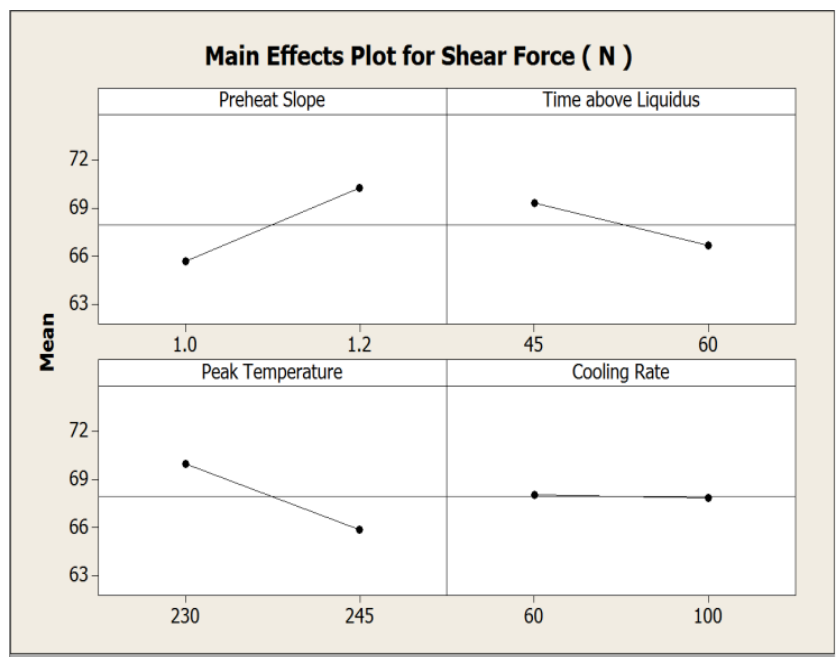

Figure 5a. Main effect plot of reflow soldering parameter on 1206 chip resistor

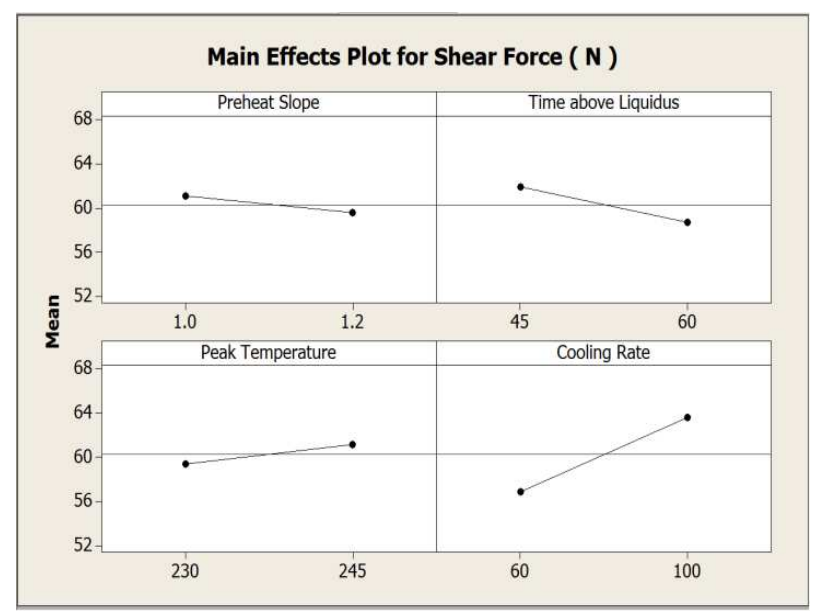

Figure 5b. Main effect plot of reflow soldering parameter on 0805 chip resistor

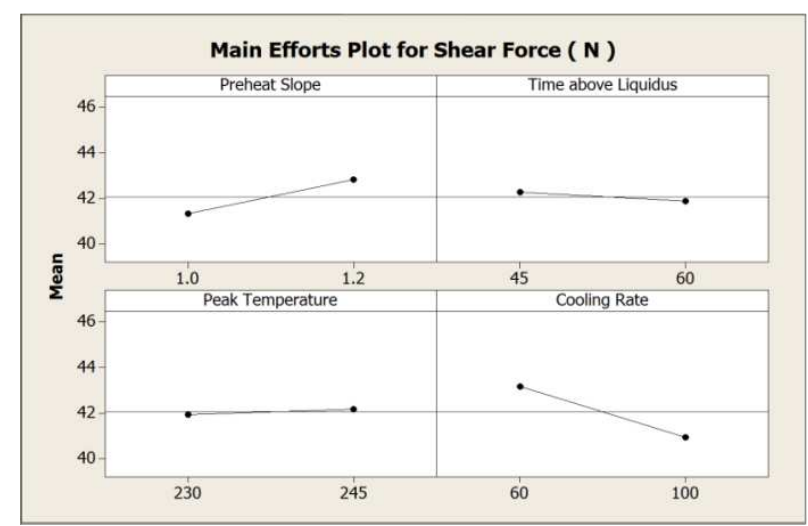

Figure 5c. Main effect plot of reflow soldering parameter on 0603 chip resistor

\section{Conclusion}

Normal probability and main effect plots have been used to provide a complete profile of the effect of reflow parameters on 1206, 0805 and 0603 chip resistor solder joint shear strength.

The normal probability plots show that some reflow profile parameters are critical and significantly affect the shear force. This is indicated by the data points that fall outside the best fit line. For instance the data point of 74.85 $\mathrm{N}$ lying outside the best fit line indicates that some of the parameters (run 2) are critical and significantly affect the response value. This means that the levels of settings can be modified to optimise the process. In the case of the 0805 chip resistor, there were no exceptional departures from the line fitted to the data. It can be assumed that the parameters and the levels considered here have no significant effect on the response. The normal probability plot of the 0603 chip resistor shows the $46.68 \mathrm{~N}$ shear strength outside the best fit line. This means that the parameters and setting (run 3) can be further modified to improve the response.

The main effect plots are used to help identify the parameters that significantly affect the response but are not known in the normal probability plots. The main effect plot shows that the parameters that affect the 1206 chip resistor are: preheat slop, peak temperature and time above liquidus. In the case of the 0803 chip resistors, the main effect plot shows slight effect by the cooling rate and time above liquidus. The parameters which affected the 0603 resistor from the main effect plot are preheat slop and cooling rate. The results of the 1206 chip resistor show the highest shear force of $74.85 \mathrm{~N}$ using a peak temperature setting of $230^{\circ} \mathrm{C}$ (low level). However, a higher temperature of $245^{\circ} \mathrm{C}$ was used in the case of the 0805 and 0603 chip resistors. The higher temperature may have contributed to the lower shear force due to the growth of brittle intermetallic compound.

\section{Acknowledgement}

The authors acknowledge the support of EMERG and University of Greenwich and staff/researchers for the work reported in this paper. 


\section{References}

[1] N.-C. Lee (1999), "Optimizing the reflow profile via defectmechanism Analysis," Soldering \& Surface MountTechnology, pp. 13-20.

[2] Ning-Cheng Lee (1997), "Reflow Soldering: Meeting the SMT Challenge", in Proc. of Nepcon West, Anaheim, CA, Feb. 1997.

[3] M. R. Harrison (2001), "Lead-free reflow soldering forelectronics assembly," Soldering \& Surface MountTechnology, vol. 13/3, pp. 21-38.

[4] Beddingfield, C., Higgins, L., (1996), "Moisture Sensitivity and Component Reliability of Flip Chip PBGA Assemblies," EPS proceedings of technical conference, pp. 26-26.

[5] Munamarty, R., McCluskey, P., (1996), "Popcorning in Fully Populated and Perimeter PlasticBall Grid Array Packages," Solder \&Surface Mount Technology, Iss: 22, pp.46-50.

[6] RanjitPandher, NavendraJodhan, Rahul Raut, and Michael Liberatore Cookson (2010) Electronics Head-in-Pillow Defect- Role of the Solder Ball Alloy, 12th Electronics Packaging Technology Conference

[7] B. Salam, C. Virsead, H. Da, N. N. Ekere, and R.Durairaj (2004), "Reflow profile study of the $\mathrm{Sn}-\mathrm{Ag}-\mathrm{Cu}$ solder "Soldering \& Surface Mount Technology, vol. 16/1, pp. 2734.

[8] H. D. Blair, T.-Y. Pan and J. M. Nicholson (1998): 48th Electronic Components and Technology Conference, pp. 259-267.

[9] H. M. Lee, S. W. Yoon and B.-J. Lee: J. Electron. Mater.27 (1998) pp.1161-1166.

[10] D. R. Frear, W. B. Jones and K. R. Kinsman: Solder Mechanics, (TMS, Warrendale, 1991) pp. 29-104.
[11] J. Pan (2006), "The effect of reflow profile on $\mathrm{SnPb}$ and SACsolder joint shear strength," Soldering \& Surface MountTechnology,vol. 18/4, pp. 48-56.

[12] Arra, M.; Shangguan, D.; Ristolainen, E.; and Lepisto, T (2002)., "Effect of Reflow Profile on Wetting and Intermetallic Formation Between $\mathrm{Sn} / \mathrm{Ag} / \mathrm{Cu}$ Solder Components and Printed Circuit Boards," Soldering and Surface Mount Technology, Vol. 14 No. 2, pp.18-25.

[13] P. Borgesen, T. Bieler, L. P. Lehman, and E. J. Cotts (2007), "Pb-free solder: New materials considerations for microelectronics processsing," MRSBull., vol. 32, no. 4, pp. 360-365.

[14] Santos, D., S. Saiyed and F. Andros, (2002). Effect of reflow profile on shear strength of $\mathrm{Sn} / 4.0 \mathrm{Ag} / 0.5 \mathrm{Cu}$ solders spheres for ball grid array applications. J. Surface Mount Technol. Assoc., 15: 25-31.

[15] Pan, J., Toleno, B.J., Chou, T. and Dee, W.J. (2006), “The effect of reflow profile on $\mathrm{SnPb}$ and $\mathrm{SnAgCu}$ solder joint shear strength", Soldering \& Surface Mount Technology, Vol. 18 No. 4, pp. 48-56.

[16] Webster, J., Pan, J. and Toleno, B.J. (2007), "Investigation of the lead-free solder joint shear performance", Journal of Microelectronic and Electronics Packaging, Vol. 4 No. 2, pp. $72-7$

[17] Milos Dusek, Martin Wickham, Christopher Hunt, (2005), The impact of thermal cycling regime on the shear strength of lead-free solder joints, Soldering \& Surface Mount Technology, Vol. 17, Issue 2, pp. 22-31

[18] Robert H. Lockner and Joseph E. Matar (1990), Designing for Quality: An Introduction to the Best of Taguchi and Western Methods of Statistical Experimental Design, Chapman and Hall, London, ISBN 0-412-40020-0 